\title{
DESAIN KNOCK-DOWN ERGONOMIS PENJERNIH AIR
}

\author{
Gempur Santoso, Yoso Wiyarno dan Poniman \\ Program Studi Teknik Industri, Fakultas Teknik, Universitas PGRI Adi Buana Surabaya \\ email: gempurbohar@yahoo.com
}

\begin{abstract}
ABSTRAK
Manusia tidak akan lepas dari kenutuhan air. Kebutuhan air merupakan kebutuhan yang mendasar bagi kehidupan. Salah satu sumber mata air yang digunakan adalah air sumur. Air sumur saat ini banyak tercemar akibat dari pencemaran limbah industri maupun limbah rumah tangga, sehingga perlu dilakukan penjernihan. Salah satu alat untuk penjernihan yaitu knock down ergonomis penjernih air. Tujuan alat ini agarmudah dibawa dan mudah untuk pemasangan serta tidak membutuhkan teknologi yang ting gi. Fung si knock down penjernih air ini digunakan untuk menurunkan kadar TDS (total dissolved solids).Tahapan penelitian meliputi tahap penelitian pendahuluan, tahap pengumpulan dan analisis data, tahap desain, dan tahap perancangan prototypelproduk. Metode pengumpulan data dengan penyebaran angket kepada responden. Sedangan analisis data menggunakan QFD (Quality Function Deployment). Hasil penelitian ini terdapat tujuh atribut tingkat kepentingan responden terhadap desain knock-down ergonomis penjernih air yang dijadikan dasar pembuatan prototype, yakni: 1) desain yang menarik,2) bahan tidak mudah korosif, 3) bahan tidak mudah pecah, 4) tahan terhadap karat, 5) produk mudah dibawa/simple,6) harga yang murah, dan 7) pemasangan yang mudah.
\end{abstract}

Kata kunci: Pencemaran Air, Penjernih air, Desain Ergonomis, QFD dan HoQ.

\begin{abstract}
Humans will not be separated from the need for water. Water needs are a basic need for life. One source of water used is well water. Water wells are currently polluted due to pollution of industrial waste and househo ld waste, so cleaning needs to be done. One of the tools for clarification is the ergonomic knock down water purifier. The purpose of this tool is to be easy to carry and easy to install and does not require high technology. The knock down function of this water purifier is used to reduce the levels of TDS (total dissolved solids). Stages of research include the preliminary research stage, the stage of data collection and analysis, the design phase, and the design phase of the prototype/product. Methods of collecting data by distributing questionnaires to respondents. While data analysis uses QFD (Quality Function Deployment). The results of this study are seven attributes of the importance of respondents to the ergonomic water purifier knock-down design that is used as the basis for making prototypes, namely: 1) attractive design, 2) non-corrosive material, 3) non-fragile material, 4) rust resistant, 5) products are easy to carry/simple, 6) low prices, and 7) easy installation.
\end{abstract}

Keywords: Water Pollution, Water Purification, Ergonomic Design, QFD and HoQ.

\section{PENDAHULUAN}

Hampir semua kegiatan yang dilakukan manusia membutuhkan air. Untuk mandi, membersihkan lantai, masak, minum, mencuci piring, mencuci baju dan lain-lain membutuhkan air. Tentu saja air yang dibutuhkan adalah air bersih. Pengadaan air bersih selain dari sumber, juga pengadaan membutuhkan alat. Filter ergonomis knok down penjernih air sebagai alternatif alat penjernih air perlu dikembangkan. Hal itu agar tidak mengalami kesulitan mendapatkan dan pengadaan air bersih.

Kebutuhan air dalam kehidupan sebagian besar didapat dari sumber air tanah dan sungai. Air permukaan terdapat dalam danau, sungai dan sumber-sumberair lainnya. Sedangkan air tanah (ground water), terdapat di dalam tanah. Air tanah dapat melarutkan mineral-mineral bahan induk dari tanah yang dilewatinya. Sebagian besar mikroorganisme yang semula ada dalam air tanah berangsur-angsur disaring 
sewaktu air meresap dalam tanah. Air yang digunakan oleh manusia adalah air permukaan tawar dan air tanah murni (Nicola, 2015). Air tanah merupakan air yang berada dibawah permukaan tanah. Karakteristik utama yang membedakan air tanah dan air permukaan adalah pergerakan air tanah yang sangat lambat dan waktu tinggal (residence time) yang sangat lama, dapat mencapai puluhan bahkan ratusan tahun (Nicola, 2015).

Menurut Wignjosoebroto (1995) dalam Rahayu (2015) Ergonomi merupakan disiplin ilmu yang mempelajari manusia dalam kaitannya dengan pekerjaannya. Ergonomi berperan dalam perancangan produk (product design) serta inovasi produk, baik pengembangan produk ataupun penciptaan produk baru. Dalam pembuatan Rancangan produk hendaknya mengacu pada prinsipprinsip ergonomis.Standar ergonomi merupakan standarisasi yang diperlukan untuk perancangan ergonomi. Standar ergonomi tersebut antara lain: standar dimensi antropometri, lingkungan fisik iklim kerja, kebisingan, dan lain-lain (Gempur Santoso, 2004). Suatu produk berpengaruh pada performen pengguna, menurut Gempur Santoso (2013) pula mengatakan bahwa performen (posisi kerja) tidak ergonomis dapat menimbulkan kelelahan, nyeri dan gangguan kesehatan lainnya.

QFD digunakan untuk memperbaiki proses perencanaan, mengatasi permasalahan dalam suatu tim, serta membantu dalam mengadakan perbaikan terhadap budaya perusahaan atau organisasi. QFD merupakan alat atau kendaraan bagi penerapan TQM dan program perbaikan mutu (Ariani, 1999). Pengembangan produk yang berbasis ergonomi sangat menentukan apakah produk yang dibuat ergonomis, penilaian ini tergantung dari konsumen sebagai pengguna. Oleh karena itu dalam penelitian ini analisis yang digunakan untuk pengembangan produk ergonomis menggunakan metode quality function deployment (QFD).
Berdasarkan uraian diatas maka rumusan masalahnya yaitu Bagaimana membuat rancangan desain filter air ergonomis knockdown dan Tujuan dari penelitian ini adalah membuat rancangan desain konockdown ergonomis penjernih air dengan metode quality function deployment ( $Q F D)$

Peraturan pemerintah No.20 tahun 1990 mengelompokkan kualitas air menjadi beberapa golongan menurut peruntukannya. Adapun penggolongan airmenurut peruntukannya adalah sebagaiberikut.

1. Golongan A, yaitu air yang dapat digunakan sebagai air minum secara langsung, tanpa pengolahan terlebih dahulu.

2. Golongan B, yaitu air yang dapat digunakan sebagai air baku air minum.

3. Golongan $\mathrm{C}$, yaitu air yang dapat digunakan untuk keperluan perikanan dan peternakan.

4. Golongan D, yaitu air yang dapat digunakan untuk keperluan pertanian, usaha diperkotaan, industri, dan pembangkit listrik tenaga air

Berdasarkan observasi awal kandungan TDS saat pengambilan data awal yaitu kandungan TDS diatas yang dipersyaratkan. Oleh karena itu perlu dilakukan pembuatan penjernih air untuk mengurangi kadar TDS. Dalam hal ini yaitu dilakukan pembuatan model filter ergonomis knock down penjernih air.

\section{METODE PENELITIAN}

\section{Tahap Pengumpulan Data}

Pengumpulan data primer diperoleh dengan cara malakukan survey lokasi pengambilan sampling air sumur untuk mengetahui kadar TDS dan penyebaran angket terhadap pengguna/konsumen yang akan dilakukan pengembangan desain dengan jumlah responden 30 orang. Data sekunder didapat dari studi literatur.

\section{Tahap Pengolahan dan Analisis Data}

Analisis data pada penelitian ini menggunakan Quality Function Deployment 
(QFD). QFD digunakan untuk mendapatkan model desain dan rancangan yang ergonomis dan sesuai permintaan konsumen. QFD digambarkan dengan sebuah matrix yang disebut "House of Quality" (HOQ) seperti pada Gambar 2 berikut ini.

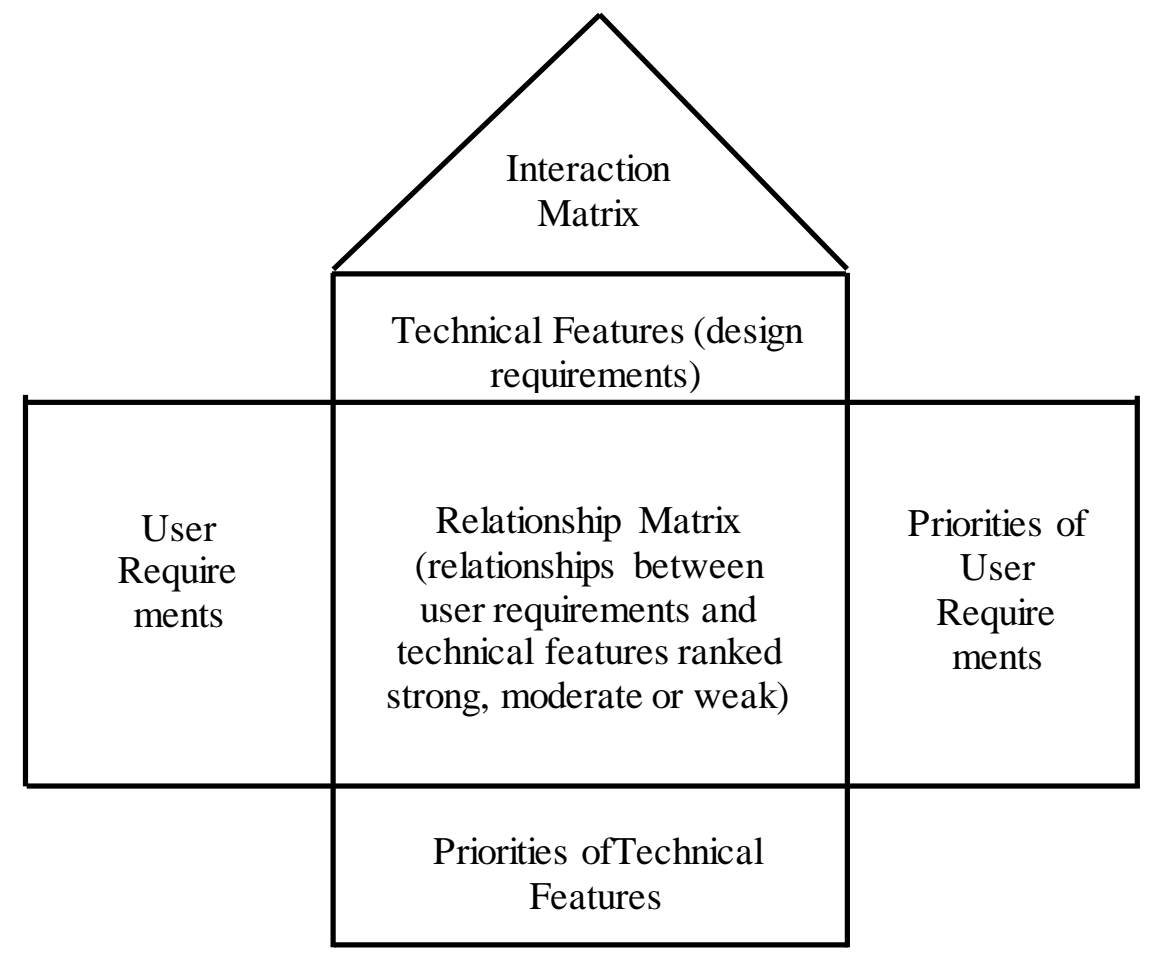

Gambar: 2 House of Quality Matrix(Demirbilek dan Demirkan, 2004)

\section{HASIL DAN PEMBAHASAN \\ 1. Atribut Technical Requirment}

Technical requirment adalah penerjemahan kebutuhan konsumen kedalam bahasa teknik.

Technical requirment didapatkan dari wawancara, penelusuran dokumen dan group discussion dengan pihak perusahaan yang memiliki kapabilitas dalam hal perancanagan Produk. Maka didapatkan informasi Technical requirment sebagai berikut:

Tabel1.Technical requirment filter air

No Technical Requirments

1 Model Knock down filter

2 Disain filter model tabung

3 Portabel filter

4 Ukuran $30 \times 16 \mathrm{~cm}$
5 Material sus 316/stainless

6 Tidak merubah instalasi air yang terpasang

7 Terdapat tas filter knockdown

8 Terdapat petunjuk pemakaian

\section{Penghitungan Raw Weightdan Normalisasi Row Weight}

- Nilai raw weight dapat digunakan sebagai dasar dalam menentukan atribut produk yang harus dikembangkan karena komponen yang ada di dalamnya cukup menyeluruh. Semakin tinggi nilai maka atribut tersebut mendapatkan prioritas yang lebih utama 
Volume 70, Nomor 2, 1 Desember 2018

Tabel 2.NilaiRaw Weightdan Normalisasi Row Weight

\begin{tabular}{|c|c|c|c|c|c|c|}
\hline No & Atribut tingakat kepentingan & $\begin{array}{c}\text { Tingkat } \\
\text { kepentingan }\end{array}$ & Improvement ratio & $\begin{array}{l}\text { Sales } \\
\text { point }\end{array}$ & Weight & $\begin{array}{c}\text { Normalisasi } \\
\text { weight \% }\end{array}$ \\
\hline 1 & Desain yang menarik & 3.84 & 1.20 & 1.5 & 6.89 & $16 \%$ \\
\hline 2 & Bahan tidak mudah korosif & 4.23 & 1.49 & 1.5 & 9.45 & $22 \%$ \\
\hline 3 & Bahan tidak mudah pecah & 3.32 & 1.29 & 1.5 & 6.43 & $15 \%$ \\
\hline 4 & Tahan terhadap karat & 3.42 & 1.35 & 1.5 & 6.91 & $16 \%$ \\
\hline 5 & Produk mudah dibawa /simple & 3.92 & 1.15 & 1 & 4.49 & $11 \%$ \\
\hline 6 & Harga yang murah & 2.58 & 1.10 & 1 & 2.84 & $7 \%$ \\
\hline 7 & Pemasangan yang mudah & 3.21 & 1.37 & 1.2 & 5.28 & $12 \%$ \\
\hline
\end{tabular}

Berdasarkan bobot pada tabel diatas menunjukan bahwa atribut tingkat kepentingan yang memiliki nilai bobot tertinggi adalah bahan tidak mudah korosif. Adapun gambar lengkap House of Quality sebagai berikut: 
Volume 70, Nomor 2, 1 Desember 2018

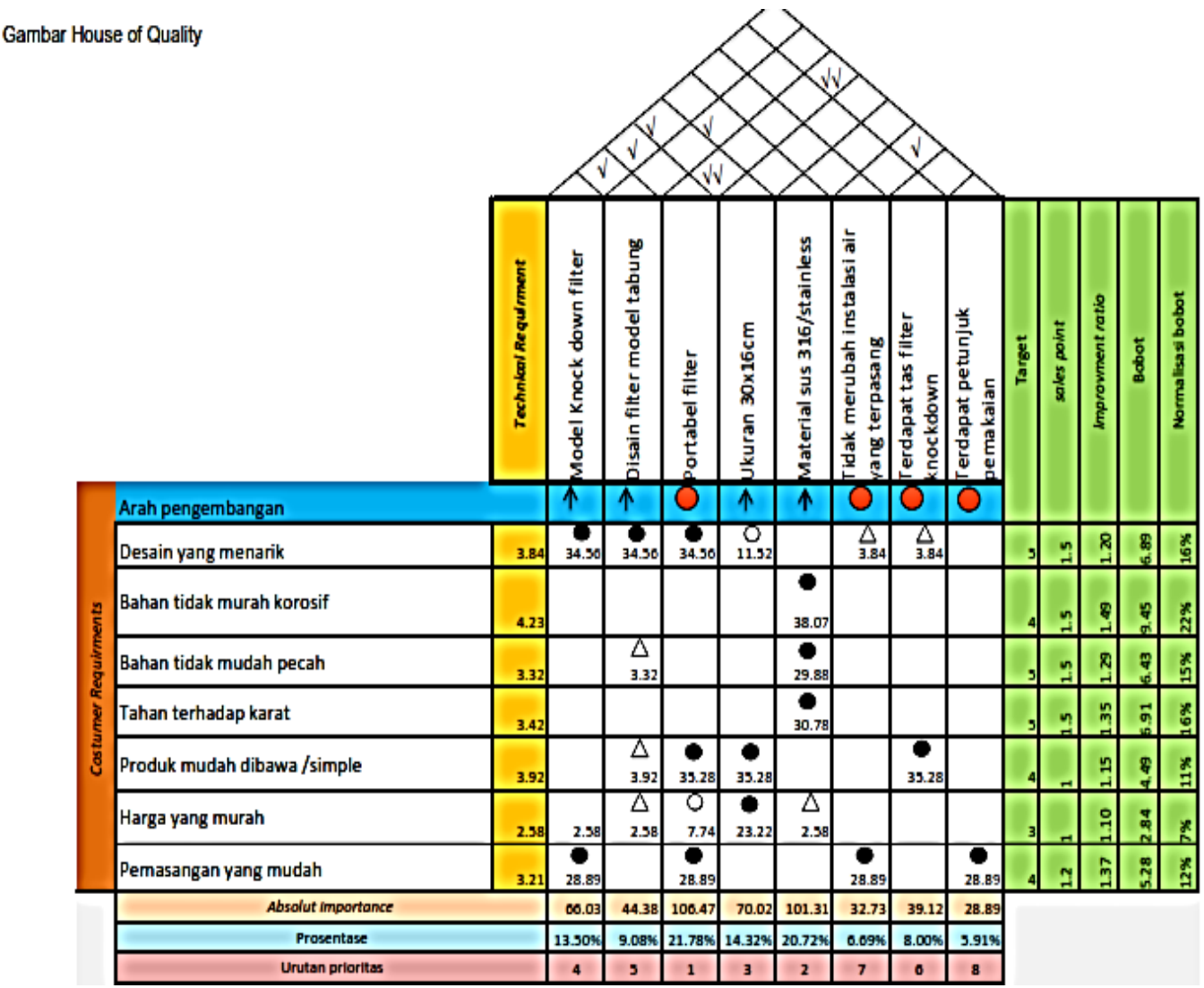

Gambar 3. HoQ Knock Down Ergonomis Penjernih Air

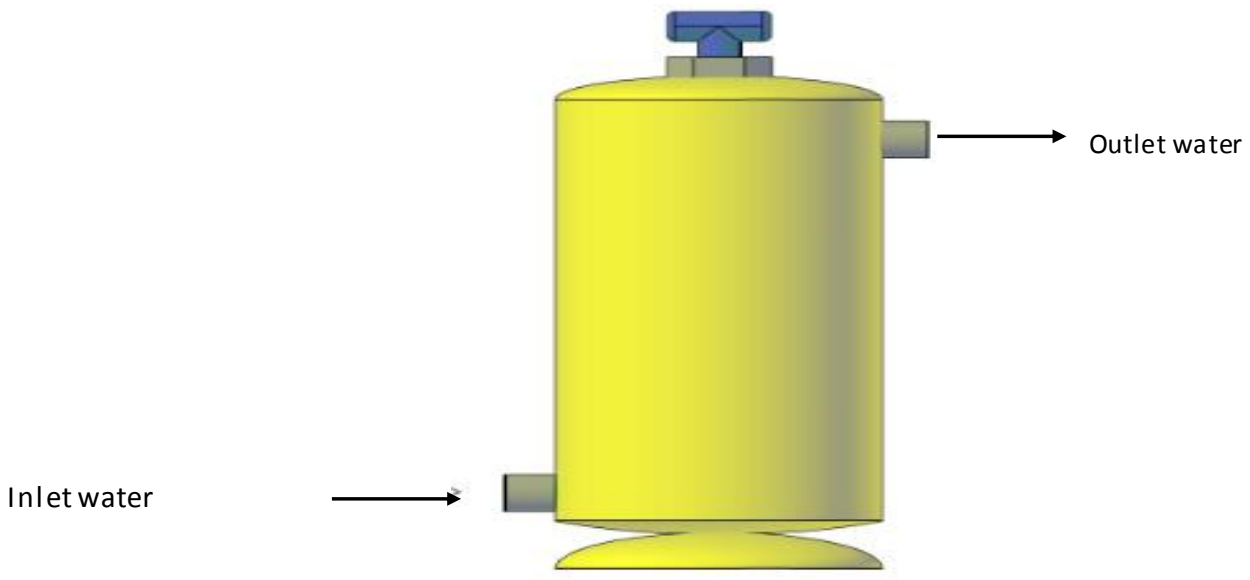

Gambar 4. Disain Knock Down Ergonomis Penjernih Air 


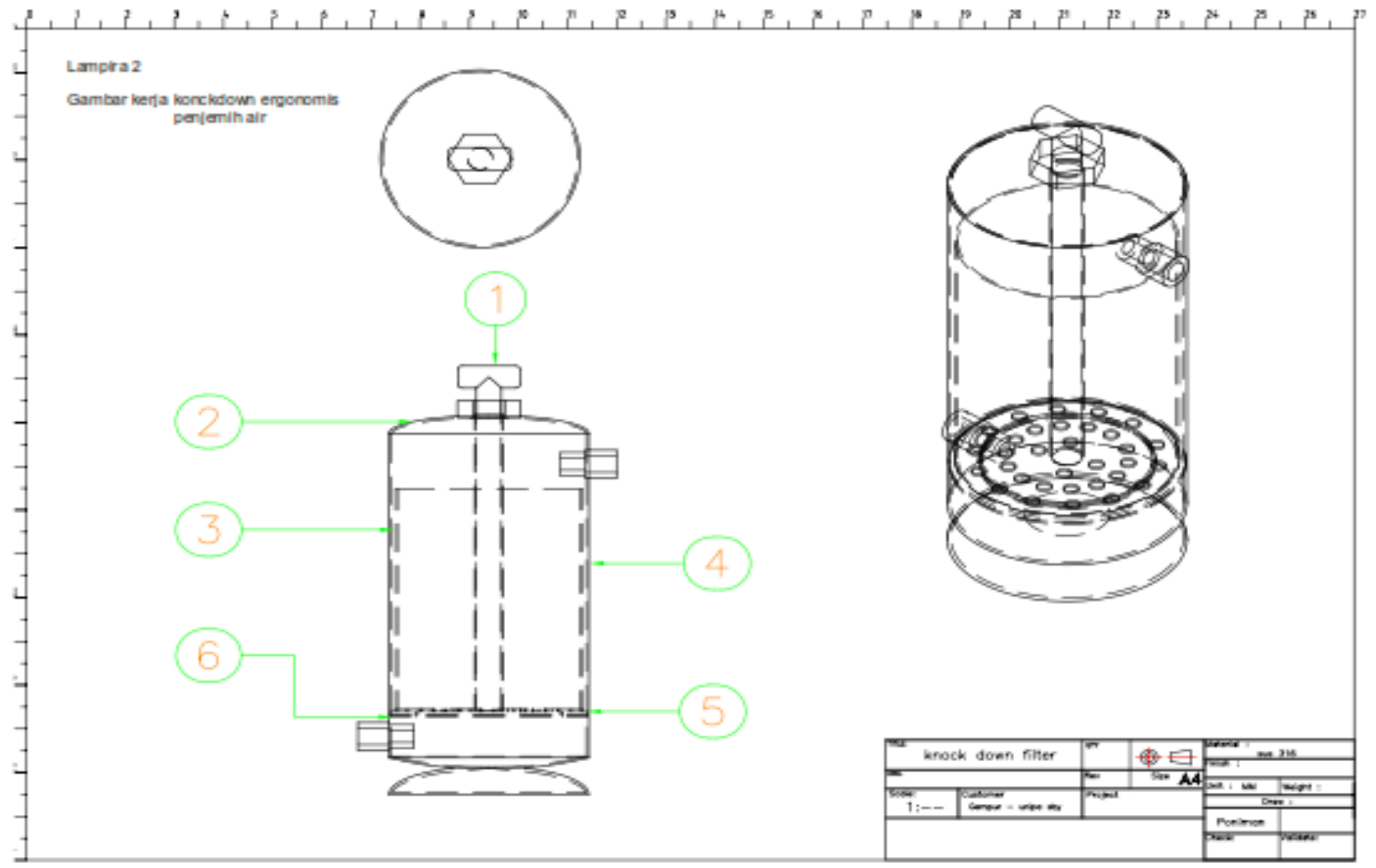

Keterangan:

1. Stutbolt; 2. Top botton; 3. Filter; 3. Casing; 4. Seal/Packing; 5.Rail pack

Gambar : 4. Layout Disain Knockdown Ergonomis Penje rnih Air

\section{KESIMPULAN}

Berdasarkan hasil analisys House of Quality (Hoq) untuk pembuatan filter air knock down ergonomis, terdapat tujuh atribut tingkat kebutuhan konsumen yaitu :1) Desain yang menarik, 2) Bahan tidak mudah korosif, 3) Bahan tidak mudah pecah, 4) Tahan terhadap karat,5) Produk mudah dibawa/simple, 6) Harga yang murah, dan 7) Pemasangan yang mudah. Saran: Untuk implementasi Quality Function Deployment filter air knock down ergonomis diharapkan berpedoman tamuan analisis Hoq sesuai kesimpulan di atas.

\section{REFERENSI}

Ariani, Wahyu Dorothea. 1999. Manajemen Mutu. Universitas Atma Jaya. Yogyakarta.
Gempur Santoso. Ergonomi Manusia, Peralatan dan Lingkungan. Prestasi Pustaka Publisher, Jakarta 2004

Gempur Santoso, 2013, Kursi ergonomis untuk menurunkan.kelelahan tenaga kerja SPBU berdasarkan fluktuasi asam laktat dan glukosa dalam darah, Jurnal Teknik "Waktu", Vol. 11 nomor 01 Januari 2013, FT Universitas PGRI Adi Buana Surabaya.

Nicola, Fendra (2015 )Hubungan Antara Konduktivitas, TDS (Total Dissolved Solid) Dan TSS (Total Suspended Solid) Dengan Kadar $\mathrm{Fe}^{2+}$ dan Fe Total Pada Air Sumur Gali. Skripsi Jurusan Kimia Fakultas Matematika Dan Ilmu Pengetahuan Alam Universitas Jember

Rahayu, N.I. (2015), Model Rotasi Pekerjaan Berdasarkan faktor ergonomi, Thesis, 
WAHANA

Volume 70, Nomor 2, 1 Desember 2018

e-ISSN : $2654-4954$, p-ISSN : $0853-4403$

Institut Teknologi Sepuluh Nopember

Surabaya 